\title{
Factors Associated with Health Behaviors in Thyroid Cancer Survivors
}

\author{
Junghyun Yoon', Boyoung Park ${ }^{2}$ \\ Departments of ${ }^{1}$ Health Sciences and ${ }^{2}$ Medicine, College of Medicine, Hanyang University, Seoul, Korea
}

\begin{abstract}
In this study, we compared health behaviors, including current smoking, drinking, and physical inactivity, in thyroid cancer survivors and non-cancer controls and investigated the factors associated with unhealthy behaviors among survivors. Baseline data from the Health Examinees study, collected from 2004 to 2013, were used. Thyroid cancer survivors ( $n=942$ ), defined as those who had received a clinical diagnosis of thyroid cancer, and 9,420 matched non-cancer controls without past history of any cancer were included in the analysis. The prevalence of smoking, alcohol consumption, and physical inactivity in thyroid cancer survivors were 2.3\%, 26.6\%, and 52.0\%, respectively, with adjusted OR (aOR) and 95\% Cl between survivors and non-cancer controls of 0.35 $(95 \% \mathrm{Cl}=0.08-1.56), 0.46(95 \% \mathrm{Cl}=0.29-0.74)$, and $0.65(95 \% \mathrm{Cl}=0.44-0.96)$. The prevalence of unhealthy behaviors was higher among male thyroid cancer survivors than female thyroid cancer survivors. In thyroid cancer survivors, those who smoked were more likely to drink $(\mathrm{aOR}=4.55[95 \% \mathrm{Cl}=1.61-12.85])$ and those who were physically inactive were less likely to drink $(\mathrm{aOR}=0.58$ $[95 \% \mathrm{Cl}=0.42-0.82])$. Current drinking and physical inactivity contributed to a higher likelihood of smoking $(\mathrm{aOR}=4.31$ [95\% $\mathrm{Cl}=$ 1.35-13.73] and 6.34 [95\% Cl = 1.65-24.34]). Thyroid cancer survivors had better health behaviors than the non-cancer controls. However, some survivors still had unhealthy lifestyles, especially displaying a clustering of unhealthy behaviors. Thus, health behavior promotion through medical intervention is important for thyroid cancer survivors.
\end{abstract}

Key Words Thyroid neoplasms, Cancer survivors, Health behavior

\section{INTRODUCTION}

Worldwide, the incidence of thyroid cancer has been on the rise. According to GLOBOCAN 2018, thyroid cancer accounted for $3.1 \%(567,233)$ of the total cancer incidence and was ranked ninth among the most common types of cancer [1]. However, the mortality associated with thyroid cancer remains unchanged [1]. In South Korea, which has seen the largest increment in prevalence despite an overall rapid decrease since 2011, thyroid cancer was the third most common cancer accounting for $11.3 \%(26,051)$ of all cancers in 2016 [2]. Over-diagnosis related to new diagnostic techniques and increased medical surveillance are considered to play a major role in this increment and even as a voluntary thyroid cancer screening within national cancer screening programs [3].

The majority of the patients diagnosed with thyroid cancer undergo total thyroidectomy, followed by lifelong thyroid replacement therapy. It was reported that people who under- went total thyroidectomy experienced more problems with health-related quality of life [4]. Of late, less invasive options are being preferred for the treatment of small papillary thyroid cancer, and the wait-and-watch approach is becoming increasingly common for patients with low-risk papillary thyroid cancer [5]. Given the relatively young age of patients at diagnosis and a survival rate that is even better than in the general population [2], in the long term, comorbidities play a major role in the lives of survivors of thyroid cancer. Studies have identified various long-term complications in thyroid cancer survivors, including cardiovascular disease [6], and aging-related problems [7]. These comorbidities are highly attributed to lifestyle factors, emphasizing the value of positive health behaviors. In general, for cancer survivors, health behaviors are becoming increasingly important to prevent recurrence of secondary cancer, comorbidities, and decline in quality of life $[8,9]$. However, morbidity and health behavior-related studies in thyroid cancer survivors have been rare, possibly because of the better survival rate as compared to other forms of can- 
cer.

Thus, we identified the prevalence of health behaviors, including current smoking, drinking, and physical inactivity, in thyroid cancer survivors and compared them with non-cancer controls. In addition, the factors associated with unhealthy behaviors among thyroid cancer survivors were investigated.

\section{MATERIALS AND METHODS}

\section{Data source and study population}

In this study, we analyzed baseline data from the Health Examinees (HEXA) study [10], a part of the Korean Genome and Epidemiology Study (KoGES) undertaken by the National Institutes of Health and Centers for Disease Control and Prevention. The KoGES is a large-scale prospective cohort study to investigate the relationship between genetic and environmental factors and chronic diseases. Questionnaires are used to collect information on sociodemographic characteristics, physical activity, drinking and smoking habits, disease treatment status, medical and family history, drug usage, and biospecimens, as well as laboratory measurement data [11]. A total of 173,357 individuals aged 40 to 79 participated in the HEXA from 2004 to 2013. Details of the HEXA design can be referred to elsewhere [10].

In this study, thyroid cancer survivors were defined as those who self-reported a clinical diagnosis on the questionnaire. Age at thyroid cancer diagnosis and current treatment status were the additional details collected. There were 942 (75 males and 867 females) subjects who had ever been diagnosed with thyroid cancer. "Cancer survivors" have been defined in varying ways by different researchers [12] and this study applied the broad definition proposed by the National Coalition for Cancer Survivorship [13] to include all individuals who had ever been diagnosed with thyroid cancer. The non-cancer controls, numbering 155,317 , were those who reported that they never been diagnosed with any type of cancer. The thyroid cancer survivors and non-cancer controls were matched by age (five-year age groups), sex, educational attainment (under high school or above college), and household income (less than $\$ 2,700 /$ mo or over $\$ 2,700 /$ mo considering the median value of household income) at a ratio of $1: 10$. Finally, the number of matched subjects included 942 survivors and 9,420 non-cancer controls in the analysis.

\section{Variables}

The outcome variables were current health behaviors, including smoking, drinking, and physical inactivity, at the time of the survey. Current smoking was defined as having smoked more than 100 cigarettes over the lifetime and being a smoker at the time of the survey. If subjects did not meet these criteria, they were classified as non-current smokers. Current drinking was defined on the basis of consuming alcohol once or more per month during the last one year. If subjects did not meet this criterion, they were classified as non-current drink- ers. According to previous guideline [14], physical inactivity was defined as $<150$ minutes of regular sweaty exercise per week.

Other variables included as covariates were age, sex, marital status (married/cohabitating, divorced/widowed/unmarried), educational attainment (under high school, above college), household income (less than $\$ 2,700 /$ mo, over $\$ 2,700$ / mo), employment status (unemployed, employed), self-rated health status (healthy, normal, or unhealthy), family history of cancer, and years since diagnosis (1-5, 6-10, or $\geq 11$ years). Comorbid chronic diseases were classified as "yes" if any of the following disease were met based on the past medical diagnosis in survey: hypertension, diabetes, dyslipidemia, stroke, transient ischemic attacks, angina or myocardial infarction, colon polyp, fatty liver, chronic liver disease or liver cirrhosis, gallbladder stone or cholecystitis, thyroid disease, arthritis, and osteoporosis. Body mass index (BMI, $\mathrm{kg} / \mathrm{m}^{2}$ ) was classified as $<25 \mathrm{~kg} / \mathrm{m}^{2}$ and $\geq 25 \mathrm{~kg} / \mathrm{m}^{2}$ according to the WHO criteria for the Asian population [15].

\section{Statistical analysis}

The baseline sociodemographic characteristics and current health behaviors of thyroid cancer survivors and non-cancer controls were compared using the independent two sample $t$-test and chi-square test. All $P$-values were two-sided and the significance level was set at 0.05 . To identify whether thyroid cancer survivors showed better or worse health behaviors (current smoking, current drinking, physical inactivity) compared with non-cancer controls, conditional logistic regression was used, adjusting for the other covariates including marital status, employment status, self-rated health status, comorbid chronic diseases, family history of cancer, years since diagnosis, investigation sites (hospital), and survey year.

To identify the baseline characteristics associated with unhealthy behaviors in thyroid cancer survivors, we conducted a multivariate logistic regression including age, sex, marital status, educational attainment, household income, employment status, self-rated health status, comorbid chronic diseases, family history of cancer, years since diagnosis, investigation sites (hospital), survey year, BMI, smoking, drinking, and physical inactivity. Any missing information on each variable was treated as dummy and included in the analysis. All analyses were performed with SAS ver. 9.4 (SAS Institute, Cary, NC, USA).

\section{RESULTS}

Table 1 depicts the sociodemographic characteristics of the 942 thyroid cancer survivors and matched 9,420 non-cancer controls. The matched variables (age, sex, educational attainment, and household income) and marital status, BMI were not different between the two groups. The other variables, which included employment status, self-rated health status, comorbid chronic diseases, and family history of cancer, 
Table 1. Comparison of sociodemographic characteristics between thyroid cancer survivors and matched non-cancer controls

\begin{tabular}{|c|c|c|c|}
\hline Characteristic & $\begin{array}{l}\text { Thyroid cancer survivors } \\
\qquad(\mathrm{n}=942)\end{array}$ & $\begin{array}{l}\text { Non-cancer controls } \\
\quad(n=9,420)\end{array}$ & $P$-value ${ }^{a}$ \\
\hline Age (yr) & $53.0(52.5-53.5)$ & $53.0(52.8-53.1)$ & 0.932 \\
\hline$<50$ & $312(33.1)$ & $3,120(33.1)$ & $>0.999$ \\
\hline $50-54$ & $250(26.5)$ & $2,500(26.5)$ & \\
\hline $55-59$ & $179(19.0)$ & $1,790(19.0)$ & \\
\hline$\geq 60$ & $201(21.4)$ & $2,010(21.4)$ & \\
\hline \multicolumn{4}{|l|}{ Sex } \\
\hline Male & $75(8.0)$ & $750(8.0)$ & $>0.999$ \\
\hline Female & $867(92.0)$ & $8,670(92.0)$ & \\
\hline \multicolumn{4}{|l|}{ Marital status } \\
\hline Divorced/widowed/unmarried & $101(10.7)$ & $1,111(11.8)$ & 0.596 \\
\hline Married/cohabitating & 837 (88.9) & $8,275(87.8)$ & \\
\hline Missing & $4(0.4)$ & $34(0.4)$ & \\
\hline \multicolumn{4}{|l|}{ Educational attainment } \\
\hline$\leq$ High school & $672(71.3)$ & $6,755(71.7)$ & 0.968 \\
\hline$>$ College & $263(27.9)$ & $2,598(27.6)$ & \\
\hline Missing & $7(0.8)$ & $67(0.7)$ & \\
\hline \multicolumn{4}{|l|}{ Household income } \\
\hline$<\$ 2,700 / \mathrm{mo}$ & $250(26.5)$ & $2,494(26.5)$ & 0.942 \\
\hline$\geq \$ 2,700 / \mathrm{mo}$ & $614(65.2)$ & $6,115(64.9)$ & \\
\hline Missing & $78(8.3)$ & $811(8.6)$ & \\
\hline \multicolumn{4}{|l|}{ Employment status } \\
\hline Unemployed & $601(63.8)$ & $5,276(56.0)$ & $<0.001$ \\
\hline Employed & $331(35.1)$ & $3,957(42.0)$ & \\
\hline Missing & $10(1.1)$ & $187(2.0)$ & \\
\hline \multicolumn{4}{|l|}{ Self-rated health status } \\
\hline Healthy & $228(24.2)$ & $3,480(37.0)$ & $<0.001$ \\
\hline Normal-unhealthy & $710(75.4)$ & $5,870(62.3)$ & \\
\hline Missing & $4(0.4)$ & $70(0.7)$ & \\
\hline \multicolumn{4}{|l|}{ Comorbid chronic diseases ${ }^{b}$} \\
\hline No & $390(41.4)$ & $5,560(59.0)$ & $<0.001$ \\
\hline Yes & $552(58.6)$ & $3,860(41.0)$ & \\
\hline \multicolumn{4}{|l|}{ Family history of cancer (any type) } \\
\hline No & $584(62.0)$ & $6,696(71.1)$ & $<0.001$ \\
\hline Yes & $354(37.6)$ & $2,686(28.5)$ & \\
\hline Missing & $4(0.4)$ & $38(0.4)$ & \\
\hline \multicolumn{4}{|l|}{ Years since diagnosis } \\
\hline $1-5$ & $574(60.9)$ & - & - \\
\hline $6-10$ & $161(17.1)$ & - & \\
\hline$\geq 11$ & $89(9.5)$ & - & \\
\hline Missing & $118(12.5)$ & - & \\
\hline \multicolumn{4}{|l|}{ Body mass index } \\
\hline$<25 \mathrm{~kg} / \mathrm{m}^{2}$ & $671(71.2)$ & $6,612(70.2)$ & 0.445 \\
\hline$\geq 25 \mathrm{~kg} / \mathrm{m}^{2}$ & $270(28.7)$ & $2,778(29.5)$ & \\
\hline Missing & $1(0.1)$ & $30(0.3)$ & \\
\hline \multicolumn{4}{|l|}{ Current smoking } \\
\hline No & $914(97.0)$ & $8,958(95.1)$ & 0.008 \\
\hline Yes & $22(2.3)$ & $418(4.4)$ & \\
\hline Missing & $6(0.7)$ & $44(0.5)$ & \\
\hline \multicolumn{4}{|l|}{ Current drinking } \\
\hline No & 687 (72.9) & $6,131(65.1)$ & $<0.001$ \\
\hline Yes & $250(26.6)$ & $3,258(34.6)$ & \\
\hline Missing & $5(0.5)$ & $31(0.3)$ & \\
\hline
\end{tabular}


Yoon and Park

Table 1. Continued

\begin{tabular}{lccc}
\hline \multicolumn{1}{c}{ Characteristic } & $\begin{array}{c}\text { Thyroid cancer survivors } \\
(\mathrm{n}=942)\end{array}$ & $\begin{array}{c}\text { Non-cancer controls } \\
(\mathrm{n}=9,420)\end{array}$ & $P$-value \\
\hline Physical inactivity & & & $<0.001$ \\
$\geq 150 \mathrm{~min} / \mathrm{wk}$ & $435(46.2)$ & $3,496(37.1)$ & \\
$<150 \mathrm{~min} / \mathrm{wk}$ & $490(52.0)$ & $5,596(59.4)$ & \\
Missing & $17(1.8)$ & $328(3.5)$ & \\
\hline
\end{tabular}

Values are presented as mean $(95 \% \mathrm{Cl})$ or number $(\%)$. ${ }^{\text {a }}$ The $P$-value is the result of the independent two sample $t$-test or chi-square test. ${ }^{\mathrm{b}}$ Chronic diseases diagnosed by a physician in the past included hypertension, diabetes, dyslipidemia, stroke, transient ischemic attacks, angina or myocardial infarction, colon polyp, fatty liver, chronic liver disease or liver cirrhosis, gallbladder stone or cholecystitis, thyroid disease, arthritis, and osteoporosis.

Table 2. Health behaviors in thyroid cancer survivors compared with non-cancer controls

\begin{tabular}{ccccc}
\hline Characteristic & Crude $\mathrm{OR}^{\mathrm{a}}(95 \% \mathrm{Cl})$ & $P$-value & Adjusted OR ${ }^{\mathrm{b}}(95 \% \mathrm{Cl})$ & $P$-value \\
\hline Current smoking & $0.48(0.31-0.75)$ & 0.001 & $0.35(0.08-1.56)$ & 0.169 \\
Current drinking $^{\text {Physical inactivity }}{ }^{\mathrm{c}}$ & $0.66(0.56-0.77)$ & $<0.001$ & $0.46(0.29-0.74)$ & 0.001 \\
\hline
\end{tabular}

${ }^{\mathrm{a} O R}$ considering only the association between each outcome (current smoking, current drinking, and physical inactivity) and group (cancer survivors and non-cancer controls). ${ }^{\text {'T }}$ The result of analyzing the thyroid cancer survivors and matched non-cancer controls by adjusting the associations of marital status, employment status, self-rated health status, comorbid chronic diseases, family history of cancer, years since diagnosis, investigation sites (hospital), and survey year with outcomes using conditional logistic regression. ${ }^{\mathrm{C}}$ Moderate-intensity aerobic exercise $<150 \mathrm{~min} / \mathrm{wk}$ was deemed physical inactivity.

showed significantly different distributions between thyroid cancer survivors and non-cancer controls.

The prevalence of current smoking, current drinking, and physical inactivity in thyroid cancer survivors was $2.3 \%, 26.6 \%$, and $52.0 \%$, respectively, and in non-cancer controls these rates were $4.4 \%, 34.6 \%$, and $59.4 \%$, respectively (Table 1 ). Therefore, the prevalence of these unhealthy behaviors was significantly lower in thyroid cancer survivors compared with matched non-cancer controls. When we stratified participants by sex, among thyroid cancer survivors, the prevalence of unhealthy behaviors was higher among males than females: smoking (13.3\% and $1.4 \%)$, drinking (57.3\% and $23.9 \%)$, and physical inactivity $(53.3 \%$ and $51.9 \%)$ (Fig. 1). Thyroid cancer survivors were less likely to be current drinking or be physically inactive than the non-cancer controls (adjusted OR $[\mathrm{aOR}]=0.46[95 \% \mathrm{Cl}=0.29-0.74]$ and $\mathrm{aOR}=0.65[95 \% \mathrm{Cl}$ $=0.44-0.96]$ ) (Table 2).

The associations between sociodemographic characteristics and health behaviors in cancer survivors are shown in Table 3. Female thyroid cancer survivors and those with a family history of cancer were less likely to be current smokers (aOR = $0.04[95 \% \mathrm{Cl}=0.01-0.22]$ and $\mathrm{aOR}=0.25[95 \% \mathrm{Cl}=0.07-$ 0.90]). Those who smoked were more likely to drink (aOR = $4.55[95 \% \mathrm{Cl}=1.61-12.85])$ and those who were physically inactive were less likely to drink $(\mathrm{aOR}=0.58[95 \% \mathrm{Cl}=0.42-$ 0.82]). With every one-year increment in age, the likelihood of female thyroid cancer survivors drinking alcohol reduced further $(\mathrm{aOR}=0.95[95 \% \mathrm{Cl}=0.93-0.98]$ and $\mathrm{aOR}=0.21$ $[95 \% \mathrm{Cl}=0.11-0.38])$. Family history of cancer was associated with a higher likelihood of current drinking $(\mathrm{aOR}=1.43$

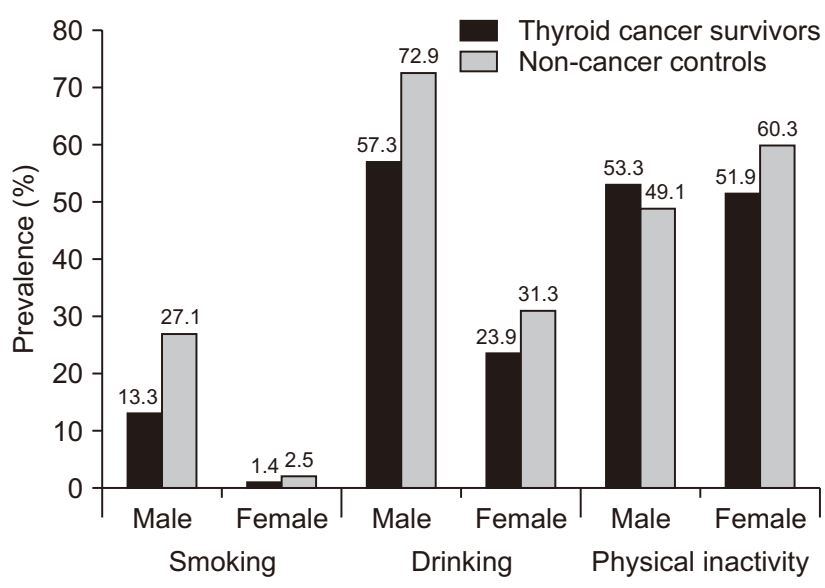

Figure 1. Prevalence of cancer survivors and non-cancer controls as well as stratified by sex.

[95\% Cl $=1.03-2.00])$. Current drinking and being physically inactive contributed to a higher likelihood of smoking (aOR = $4.31[95 \% \mathrm{Cl}=1.35-13.73]$ and $\mathrm{aOR}=6.34[95 \% \mathrm{Cl}=1.65-$ 24.34]). Thyroid cancer survivors who were employed, had lower self-rated health status (normal or unhealthy), and were current smokers were associated with higher physical inactivity $(\mathrm{aOR}=1.73[95 \% \mathrm{Cl}=1.26-2.39]$, aOR $=1.48[95 \% \mathrm{Cl}=$ $1.05-2.08]$, and aOR $=6.21[95 \% \mathrm{Cl}=1.87-20.56]$, respectively). Those with comorbid chronic diseases and current drinkers were more likely to be physically active $(\mathrm{aOR}=0.71$ $[95 \% \mathrm{Cl}=0.52-0.96]$ and $\mathrm{aOR}=0.59[95 \% \mathrm{Cl}=0.42-0.83]$ ). 
Table 3. Association between sociodemographic characteristics and health behaviors among thyroid cancer survivors

\begin{tabular}{|c|c|c|c|c|c|c|}
\hline \multirow{2}{*}{ Characteristic } & \multicolumn{2}{|c|}{ Current smoking } & \multicolumn{2}{|c|}{ Current drinking } & \multicolumn{2}{|c|}{ Physical inactivity ${ }^{a}$} \\
\hline & aOR $(95 \% \mathrm{Cl})^{\mathrm{b}}$ & $P$-value & aOR $(95 \% \mathrm{Cl})^{\mathrm{b}}$ & $P$-value & aOR $(95 \% \mathrm{Cl})^{\mathrm{b}}$ & $P$-value \\
\hline Age, one-year increment & $0.90(0.83-0.99)$ & 0.021 & $0.95(0.93-0.98)$ & $<0.001$ & $0.99(0.96-1.01)$ & 0.226 \\
\hline \multicolumn{7}{|l|}{ Sex } \\
\hline Male & 1 & & 1 & & 1 & \\
\hline Female & $0.04(0.01-0.22)$ & $<.001$ & $0.21(0.11-0.38)$ & $<0.001$ & $1.05(0.58-1.91)$ & 0.864 \\
\hline \multicolumn{7}{|l|}{ Marital status } \\
\hline Divorced/widowed/unmarried & 1 & & 1 & & 1 & \\
\hline Married/cohabitating & $0.49(0.09-2.83)$ & 0.425 & $0.79(0.45-1.37)$ & 0.393 & $0.78(0.48-1.27)$ & 0.317 \\
\hline \multicolumn{7}{|l|}{ Educational attainment } \\
\hline$\leq$ High school & 1 & & 1 & & 1 & \\
\hline$>$ College & $0.49(0.11-2.13)$ & 0.339 & $0.64(0.43-0.95)$ & 0.028 & $1.28(0.90-1.83)$ & 0.166 \\
\hline \multicolumn{7}{|l|}{ Household income } \\
\hline$<\$ 2,700 / \mathrm{mo}$ & 1 & & 1 & & 1 & \\
\hline$\geq \$ 2,700 / \mathrm{mo}$ & $1.53(0.36-6.51)$ & 0.566 & $0.94(0.62-1.43)$ & 0.769 & $0.83(0.57-1.19)$ & 0.304 \\
\hline \multicolumn{7}{|l|}{ Employment status } \\
\hline Unemployed & 1 & & 1 & & 1 & \\
\hline Employed & $0.70(0.21-2.37)$ & 0.565 & $1.19(0.83-1.70)$ & 0.349 & $1.73(1.26-2.39)$ & 0.001 \\
\hline \multicolumn{7}{|l|}{ Self-rated health status } \\
\hline Healthy & 1 & & 1 & & 1 & \\
\hline Normal-unhealthy & $1.54(0.44-5.42)$ & 0.503 & $0.74(0.50-1.09)$ & 0.124 & $1.48(1.05-2.08)$ & 0.024 \\
\hline \multicolumn{7}{|l|}{ Comorbid chronic diseases ${ }^{c}$} \\
\hline No & 1 & & 1 & & 1 & \\
\hline Yes & $1.03(0.30-3.55)$ & 0.968 & $0.76(0.54-1.07)$ & 0.118 & $0.71(0.52-0.96)$ & 0.026 \\
\hline \multicolumn{7}{|l|}{ Family history of cancer (any type) } \\
\hline No & 1 & & 1 & & 1 & \\
\hline Yes & $0.25(0.07-0.90)$ & 0.034 & $1.43(1.03-2.00)$ & 0.034 & $0.99(0.74-1.33)$ & 0.942 \\
\hline \multicolumn{7}{|l|}{ Years since diagnosis } \\
\hline $1-5$ & 1 & & 1 & & 1 & \\
\hline $6-10$ & $0.96(0.21-4.37)$ & 0.953 & $1.32(0.85-2.04)$ & 0.220 & $1.77(1.19-2.63)$ & 0.005 \\
\hline$\geq 11$ & $1.78(0.26-12.07)$ & 0.555 & $1.35(0.77-2.36)$ & 0.293 & $0.82(0.50-1.34)$ & 0.425 \\
\hline \multicolumn{7}{|l|}{ Body mass index } \\
\hline$<25 \mathrm{~kg} / \mathrm{m}^{2}$ & 1 & & 1 & & 1 & \\
\hline$\geq 25 \mathrm{~kg} / \mathrm{m}^{2}$ & $1.22(0.38-3.91)$ & 0.734 & $1.05(0.73-1.50)$ & 0.806 & $1.01(0.74-1.37)$ & 0.968 \\
\hline \multicolumn{7}{|l|}{ Current smoking } \\
\hline No & - & & 1 & & 1 & \\
\hline Yes & - & & $4.55(1.61-12.85)^{f}$ & 0.004 & $6.21(1.87-20.56)^{g}$ & 0.003 \\
\hline \multicolumn{7}{|l|}{ Current drinking } \\
\hline No & 1 & & - & & 1 & \\
\hline Yes & $4.31(1.35-13.73)^{d}$ & 0.014 & - & & $0.59(0.42-0.83)$ & 0.002 \\
\hline \multicolumn{7}{|l|}{ Physical inactivity } \\
\hline$\geq 150 \mathrm{~min} / \mathrm{wk}$ & 1 & & 1 & & - & \\
\hline$<150 \mathrm{~min} / \mathrm{wk}$ & $6.34(1.65-24.34)^{\mathrm{e}}$ & 0.007 & $0.58(0.42-0.82)$ & 0.002 & - & \\
\hline
\end{tabular}

${ }^{\mathrm{a}}$ Thyroid cancer survivors who did not exercise at moderate intensity for $>150 \mathrm{~min} / \mathrm{wk} .{ }^{\mathrm{b}} \mathrm{The}$ adjusted ORs (aORs) were adjusted for the variables in the tables, in addition to investigation sites (hospital), and survey year. ${ }^{\circ}$ Chronic diseases diagnosed by a physician in the past included hypertension, diabetes, dyslipidemia, stroke, transient ischemic attacks, angina or myocardial infarction, colon polyp, fatty liver, chronic liver disease or liver cirrhosis, gallbladder stone or cholecystitis, thyroid disease, arthritis, and osteoporosis. ${ }^{\mathrm{d}-\mathrm{g}}$ Since the range of $\mathrm{Cl}$ was very wide, the number of cases and total (case/total) was presented as 15/22, 17/22, 15/250, and 17/490, respectively.

\section{DISCUSSION}

In this study, we compared the health behaviors of thyroid cancer survivors and non-cancer controls and identified factors related to unhealthy behaviors in survivors. Current alcohol consumption and physical inactivity in thyroid cancer survivors were significantly lower than non-cancer controls.
When classified by sex, the prevalence of unhealthy behaviors was higher in male thyroid cancer survivors than in female thyroid cancer survivors.

Previous studies with representative subjects in western and Korean countries have shown that cancer survivors had better behavior than non-cancer controls in smoking and drinking $[16,17]$. While others have demonstrated that nega- 
tive health behaviors are more common in cancer survivorshigher current smoking rates, particularly among younger [18] and gynecological cancer survivors [19], higher rates of alcohol consumption [18], and a higher likelihood of being physically inactive [19]. Even among cancer survivors, the pattern of health behaviors has been shown to differ according to the type of cancer, such as more negative behaviors in cervical cancer survivors [20]. Such results might be attributed to the different disease characteristics, risk factors, patients' and survivors' characteristics by cancer type.

Regarding thyroid cancer, the survival rate of which is better than other types of cancer, quality of life, associated sociodemographic factors, health behavioral factors, and medical factors have previously been investigated [21]. A previous study showed that the nutrition intake in thyroid cancer survivors was comparable to that of the general population, except for the slightly higher intake of calcium and iron, and differed from the intake of survivors of other major cancers, with higher carbohydrate and lower fat and protein consumption [22], suggesting that the eating pattern of thyroid cancer survivors is similar to the general population. However, in terms of health behaviors, thyroid cancer survivors showed more positive behaviors than survivors of other types of cancer $[16,17]$.

Another finding of this study concerns the clustering of health behaviors. Current smoking was correlated with higher alcohol consumption and physical inactivity. This kind of clustering has been observed in previous study on cancer survivors [16] as well as the general population [23]. One notable finding in the present study was that there was a negative correlation between physical inactivity and current alcohol consumption; in other words, those who were physically active were more likely to be current drinkers. This finding was not consistent with previous studies [16,23]. In South Korea, drinking is considered a way of maintaining a sense of community and is a part of work and leisure gatherings [24]. It is considered that there is a significant correlation between social networks and exercise behavior [25]. Thus, physically active survivors might have had more opportunities to develop social relationships and consume alcohol.

While it is known that females have better health-related lifestyles than males in the general population and cancer survivors [26,27], interestingly, studies show that the prevalence of smoking is higher in female cancer survivors than non-cancer subjects with significant sex-drinking/smoking interaction [17]. However, in this study, female thyroid cancer survivors showed healthier behaviors than male thyroid cancer survivors in terms of both smoking and drinking but did not show differences in physical activity. In South Korea, the prevalence of smoking and drinking in the general population is much higher in males than females, but the prevalence of physical activity does not vary much by sex, and this pattern seems to have been reflected in the population of thyroid cancer survivors as well [28].
The result of the association between increments in age and the lower likelihood of current drinking in this study was also observed in other study [16]. The associations between employment, self-rated health status, and higher physical inactivity as well as the correlation between comorbidities and lower physical inactivity were comparable with a previous study on gastric cancer survivors [27]. Long working hours could be a reason for the increased physical inactivity in employees. Higher physical inactivity in cancer survivors with lower self-rated health status was observed in a previous study [29] as well as the general population [30]. Reports of lower physical inactivity in survivors with comorbidities contradicted what was observed in our study [31]. As thyroid cancer survivors have a better survival rate than survivors of other types of cancer, those with chronic diseases may have opportunities to be educated about the importance of exercise during their visits to primary physicians, rather than cancer specialists who are mostly focused on treatment [32].

Several limitations of this study should be mentioned. First, those who had undergone medical examination at urban cities were recruited as participants in the HEXA study; thus, they may not be representative of the South Korean population, especially those who do not participate in health examinations or lived in rural areas. Therefore, thyroid cancer survivors selected from HEXA participants may not be representative of all thyroid cancer survivors as well. Second, thyroid cancer survivors who died before the study or were hospitalized or in care centers did not have the chance to participate in the HEXA study. Third, thyroid cancer survivors were identified based on the response to the question regarding past disease history; therefore, the determination of the study population may have been faulty. However, previous study on cancer survivors identified the target populations in the same manner as us [17]. Self-reported cancer history has been reported to be valid, especially the positive predictive value of thyroid cancer was $96.1 \%$, which was the highest compared to other cancers [33]. Fourth, information on thyroid cancer stage and specific treatments was not available. In addition, patients with other cancers prior to thyroid cancer were included in the analysis as thyroid survivors, despite patients with multiple sites of cancer have distinct characteristics compared with other cancer survivors with single site. However, as the number of patients with other cancer histories was smaller than that of all thyroid cancer survivors (24 of 924), the effect on the analysis results is considered to be insignificant. Fifth, unhealthy behaviors such as smoking, drinking, and physical inactivity could have been under-reported because of social desirability bias. Finally, we applied baseline data of the HEXA study, thus temporal relationships or causality could not be assessed.

Despite these limitations, as per the authors' knowledge, this is the first study to investigate health behaviors and their associated factors in a relatively large sample of thyroid cancer survivors. In addition, thyroid cancer survivors 
were matched by sex, age, educational level, and income to non-cancer controls to increase comparability between the two groups.

In conclusion, this study identified significant differences in the prevalence of thyroid cancer survivors and non-cancer controls based on several sociodemographic factors and health behaviors, such as smoking, alcohol consumption, and physical inactivity. Notably, we observed comparison of unhealthy behaviors among thyroid cancer survivors, which has not been reported in the literature. As thyroid cancer has a high survival rate and an increasing number of survivors, management, including health behaviors, is becoming an important issue. Compared to the non-cancer control group, thyroid cancer survivors had good lifestyles, but the clustering of unhealthy behaviors made it difficult to maintain good behaviors after thyroid cancer diagnosis. Based on identification of thyroid cancer survivors' health behaviors, there is a need for opportunities to improve their quality of life through medical intervention.

\section{ACKNOWLEDGMENTS}

The research was supported by the grant funded in 2019 by the Korean Foundation for Cancer Research, Seoul, Republic of Korea.

\section{CONFLICTS OF INTEREST}

No potential conflicts of interest were disclosed.

\section{ORCID}

Junghyun Yoon, https://orcid.org/0000-0003-0356-6037

Boyoung Park, https://orcid.org/0000-0003-1902-3184

\section{REFERENCES}

1. Bray F, Ferlay J, Soerjomataram I, Siegel RL, Torre LA, Jemal A. Global cancer statistics 2018: GLOBOCAN estimates of incidence and mortality worldwide for 36 cancers in 185 countries. CA Cancer J Clin 2018;68:394-424.

2. Jung KW, Won YJ, Kong HJ, Lee ES. Cancer statistics in Korea: incidence, mortality, survival, and prevalence in 2016. Cancer Res Treat 2019;51:417-30.

3. Vaccarella S, Franceschi S, Bray F, Wild CP, Plummer M, Dal Maso L. Worldwide thyroid-cancer epidemic? The increasing impact of overdiagnosis. N Engl J Med 2016;375:614-7.

4. Nickel B, Tan T, Cvejic E, Baade P, McLeod DSA, Pandeya N, et al. Health-related quality of life after diagnosis and treatment of differentiated thyroid cancer and association with type of surgical treatment. JAMA Otolaryngol Head Neck Surg 2019;145:231-8.

5. Iñiguez-Ariza NM, Brito JP. Management of low-risk papillary thyroid cancer. Endocrinol Metab (Seoul) 2018;33:185-94.

6. Park J, Blackburn BE, Ganz PA, Rowe K, Snyder J, Wan Y, et al. Risk factors for cardiovascular disease among thyroid cancer survivors: findings from the Utah Cancer Survivors Study. J Clin Endocrinol Metab 2018;103:2468-77.

7. Blackburn BE, Ganz PA, Rowe K, Snyder J, Wan Y, Deshmukh $\mathrm{V}$, et al. Aging-related disease risks among young thyroid cancer survivors. Cancer Epidemiol Biomarkers Prev 2017;26:1695704.

8. Demark-Wahnefried W, Jones LW. Promoting a healthy lifestyle among cancer survivors. Hematol Oncol Clin North Am 2008;22:319-42, viii.

9. Ganz PA. Late effects of cancer and its treatment. Semin Oncol Nurs 2001;17:241-8.

10. Health Examinees Study Group. The Health Examinees (HEXA) study: rationale, study design and baseline characteristics. Asian Pac J Cancer Prev 2015;16:1591-7.

11. Kim Y, Han BG; KoGES group. Cohort profile: the Korean Genome and Epidemiology Study (KoGES) consortium. Int J Epidemiol 2017;46:1350.

12. Mayer DK, Nasso SF, Earp JA. Defining cancer survivors, their needs, and perspectives on survivorship health care in the USA. Lancet Oncol 2017;18:e11-8.

13. Rowland JH, Hewitt M, Ganz PA. Cancer survivorship: a new challenge in delivering quality cancer care. J Clin Oncol 2006;24:5101-4.

14. Piercy KL, Troiano RP, Ballard RM, Carlson SA, Fulton JE, Galuska DA, et al. The Physical Activity Guidelines for Americans. JAMA 2018;320:2020-8.

15. WHO Expert Consultation. Appropriate body-mass index for Asian populations and its implications for policy and intervention strategies. Lancet 2004;363:157-63.

16. Park B, Kong SY, Kim J, Kim Y, Park IH, Jung SY, et al. Health behaviors of cancer survivors in nationwide cross-sectional survey in Korea: higher alcohol drinking, lower smoking, and physical inactivity pattern in survivors with higher household income. Medicine (Baltimore) 2015;94:e1214.

17. Mowls DS, Brame LS, Martinez SA, Beebe LA. Lifestyle behaviors among US cancer survivors. J Cancer Surviv 2016;10:692-8.

18. Eakin EG, Youlden DR, Baade PD, Lawler SP, Reeves MM, Heyworth JS, et al. Health behaviors of cancer survivors: data from an Australian population-based survey. Cancer Causes Control 2007;18:881-94

19. Linsky A, Nyambose J, Battaglia TA. Lifestyle behaviors in Massachusetts adult cancer survivors. J Cancer Surviv 2011;5:27-34.

20. Park B, Kim SI, Seo SS, Kang S, Park SY, Lim MC. Health behaviors and associated sociodemographic factors in cervical cancer survivors compared with matched non-cancer controls. PLoS One 2016;11:e0160682.

21. Hoftijzer HC, Heemstra KA, Corssmit EP, van der Klaauw AA, Romijn JA, Smit JW. Quality of life in cured patients with differentiated thyroid carcinoma. J Clin Endocrinol Metab 2008;93:200-3.

22. Park B, Lee J, Kim J. Imbalanced nutrient intake in cancer 
survivors from the examination from the nationwide health examination center-based cohort. Nutrients 2018;10:212.

23. Mawditt C, Sacker A, Britton A, Kelly Y, Cable N. The clustering of health-related behaviours in a British population sample: testing for cohort differences. Prev Med 2016;88:95-107.

24. Chun S. The social meaning of alcohol consumption in Korea. J Korean Diabetes 2012;13:57-60.

25. McAuley E, Jerome GJ, Marquez DX, Elavsky S, Blissmer B. Exercise self-efficacy in older adults: social, affective, and behavioral influences. Ann Behav Med 2003;25:1-7.

26. Fleming PJ, Agnew-Brune C. Current trends in the study of gender norms and health behaviors. Curr Opin Psychol 2015;5:72-7.

27. Kim M, Choi KS, Suh M, Jun JK, Chuck KW, Park B. Risky lifestyle behaviors among gastric cancer survivors compared with matched non-cancer controls: results from baseline result of community based cohort study. Cancer Res Treat 2018;50:73847.

28. Korea Centers for Disease Control and Prevention. Website of Korea National Health and Nutrition Examination Survey. https:// knhanes.cdc.go.kr/knhanes/eng/index.do. Accessed August 28,
2019.

29. Lee HY, Kim J, Merighi JR. Physical activity and self-rated health status among older adult cancer survivors: does intensity of activity play a role? Oncol Nurs Forum 2015;42:614-24.

30. Cimarras-Otal C, Calderón-Larrañaga A, Poblador-Plou B, González-Rubio F, Gimeno-Feliu LA, Arjol-Serrano JL, et al. Association between physical activity, multimorbidity, self-rated health and functional limitation in the Spanish population. BMC Public Health 2014;14:1170.

31. Gjerset GM, Fosså SD, Courneya KS, Skovlund E, Thorsen L. Exercise behavior in cancer survivors and associated factors. J Cancer Surviv 2011;5:35-43.

32. Yang EJ, Chung SH, Jeon JY, Seo KS, Shin HI, Hwang JH, et al. Current practice and barriers in cancer rehabilitation: perspectives of Korean physiatrists. Cancer Res Treat 2015;47:370-8.

33. Cho S, Shin A, Song D, Park JK, Kim Y, Choi JY, et al. Validity of self-reported cancer history in the health examinees (HEXA) study: a comparison of self-report and cancer registry records. Cancer Epidemiol 2017;50(Pt A):16-21. 